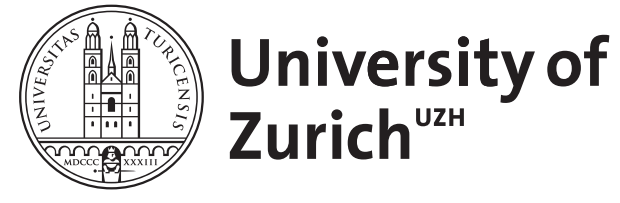
Archive

University of Zurich

University Library

Strickhofstrasse 39

CH-8057 Zurich

www.zora.uzh.ch

Year: 2005

\title{
Kinship and Behavior in Primates
}

van Schaik, Carel

DOI: https://doi.org/10.1007/s10764-005-8862-x

Posted at the Zurich Open Repository and Archive, University of Zurich

ZORA URL: https://doi.org/10.5167/uzh-156182

Journal Article

Published Version

Originally published at:

van Schaik, Carel (2005). Kinship and Behavior in Primates. International Journal of Primatology, 26(6):1475-1477.

DOI: https://doi.org/10.1007/s10764-005-8862-x 


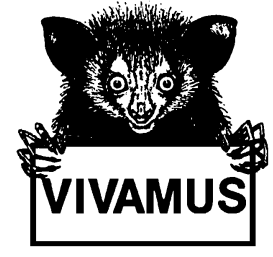

\section{Book Review}

Kinship and Behavior in Primates. Edited by Bernard Chapais and Carol M. Berman, Oxford University Press, Oxford, UK,2004. USD 85.00 $x i i+507 \mathrm{pp}$.

Hamilton's theory of kin selection paved the way for sociobiology and its intellectual offspring, behavioral ecology and evolutionary psychology. Many probably believe that 40 years later, we have learned all there is to learn about kinship and social behavior. However, tests of Hamilton's theory in primates have been limited: Building up knowledge of genealogies in these slow-breeding organisms used to take years, and the paternal component or relatedness could only be estimated. Indeed, a long-running debate has centered on the possible recognition of paternal kinship by the animals themselves. Moreover, exactly how kin should deploy their altruism remains a thorny theoretical issue.

The molecular revolution holds great promise for solving these problems. The first section of this massive volume (20 chapters, 507 densely printed pages) contains 2 excellent chapters (by Morin and Goldberg and by Woodruff) on genetic techniques. It is striking how rarely primate field studies have applied these new techniques to estimate relatedness. Yet, although some important studies (e.g., by Theresa Pope) have confirmed the importance of kinship in residence and alliance maintenance, multiple studies on chimpanzees have suggested that males do not preferentially select (maternal) kin to form alliances with, and that they do not even show far higher average relatedness values than the females, despite being philopatric. We can be sure that new studies will produce major surprises.

Kinship affects unidirectional altruism, reciprocity, exchange, and mutualism. Chapais and Bélisle ably reveal the complex issues surrounding Hamilton's seemingly simple idea, and offer the important suggestion that cooperative acts that rely on special skills or competences in the partners are linked less tightly to relatedness. In all animals but humans, these 
behaviors require the physical proximity of kin, but the opposite is true for the other major kind of social behavior linked to kinship, mating behavior. It is now known that inbreeding avoidance is widespread and underlies sex differences in dispersal. Dispersal, and sex differences in it, are therefore essential to understand the patterns of kin-directed behavior in primates. Isbell wrestles with the ecological bases for differential dispersal, while Hoelzer et al. explore the consequences of sex differential dispersal on the genetic landscape. Several subsequent chapters offer fine overviews of the natural history of kinship and behavior in primates with different dispersal regimes (Kapsalis, Strier, Nash).

As expected, a theme that returns in quite a few chapters is the extent to which paternal kin is recognized. Paul and Kuester, in their excellent contribution, stress that most work to date found no effect of paternal kinship, especially on inbreeding avoidance, but a few recent studies indicate an effect on proximity and agonistic support. These discrepancies need to be reconciled in future work. Closely related to this important question is the mechanism of kin recognition. In a stimulating review, Rendall stresses how little we know about the actual mechanisms of kin recognition in primates beyond the mother-based familiarity. Berman focuses on the ontogeny of kin recognition.

Two interesting chapters are not easily classified. Dietz uses long-term data on the helper systems of golden lion tamarins to test different skew models (kinship among group members features in the predictions of different models). Cheney and Seyfarth discuss experiments showing that members of monkey groups know the kin relationships among the members of their group, and that such classifications are unlikely to merely reflect associative conditioning.

Perhaps the most useful section for primatologists is the one on humans. Rodseth and Wrangham show that human societies differ fundamentally from all of those of nonhuman primates. We invented a new class of "kin" (affinal "relatives," such as spouses), we extended bonds beyond co-residence, thereby making the actual residence pattern less important to alliance maintenance, and we began to use our sexual alliances (marriage) to forge political relationships between the alliances to which each spouse belongs. Our societies therefore no longer correspond to the traditional group or society of nonhuman primates. Alvarez's very useful reassessment of the old ethnographies serves to dismiss a false fact: hunter-gatherer bands are not typically patrilocal, but instead have highly flexible residential patterns, with bilocality the most common one. The chapter stands as a cautionary tale for primatologists too eager to connect chimpanzees to humans, ignoring 7 million years of separate evolution and numerous species and hence lifestyles in between. Finally, Hawkes dissects our most 
important non-kinship form of relatedness: our pair bond. She marshals numerous findings to dismiss the textbook explanation that paternal processing of offspring provided the major selective benefit. Like Rodseth and Wrangham, she favors an exploitation based on protection against coercion, bolstering the confidence that primatologists can have in the significance of our work for understanding the human condition.

The book succeeds both at summarizing what we know and at reminding us of what we do not know: kin selection is far from done! Graduate students in primate behavior can find many good research topics in this book, especially if they apply the new genetic techniques discussed in some chapters to the questions developed in others.

Carel van Schaik

Anthropologisches Institut und Museum

Universität Zürich

Winterthurerstrasse 190

85057-CH, Switzerland 